\title{
Population status and distribution of the Endangered yellow-margined box turtle Cuora flavomarginata in Taiwan
}

\author{
Yi-Fu Lin, Sheng-Hai Wu, Te-En Lin, Jean - Jay Ma o and Tien-Hi Chen
}

\begin{abstract}
The Chelonia face an extinction crisis, particularly in Asia: unsustainable harvests, and habitat fragmentation and loss accompanying rapid urbanization and land development all pose threats to turtles. These threats are particularly acute for those species with a high commercial value such as the yellow-margined box turtle Cuora flavomarginata. Because of burgeoning demand in the food and pet markets, combined with extensive habitat loss, C. flavomarginata is categorized as Endangered on the IUCN Red List. To investigate the status and distribution of this species in Taiwan we conducted an extensive trapping survey in 2001-2008, locating a total of 527 different individuals at 23 sites. Our results show that $C$. flavomarginata is restricted to low-elevation forested hills. Populations in lowland areas may have been extirpated by land development. There are four clusters of localities in low-elevation primary and secondary forests, and some relatively large populations survive. However, capture success at most sites was low. In those sites where we trapped $>20$ individuals, sex ratios were significantly skewed towards females and adults predominated. The most essential measure for the conservation of C. flavomarginata in Taiwan is to secure and preserve some relatively undisturbed habitats at low elevations.
\end{abstract}

Keywords Chelonia, Cuora flavomarginata, distribution, population status, Taiwan, yellow-margined box turtle

\section{Introduction}

The Chelonia face an extinction crisis, particularly in Asia, because of the burgeoning demands for the pet, food and traditional Chinese medicine markets (Gibbons et al., 2000; van Dijk et al., 2000). Unsustainable harvests, and habitat fragmentation and loss accompanying rapid

YI-Fu Lin and SHeNG-HaI Wu Department of Life Sciences, National Chung Hsing University, Taichung 402, Taiwan

Te-En Lin Taiwan Endemic Species Research Institute, Chichi 552, Nantou County, Taiwan

JEAN-JAY MAO Department of Forestry and Natural Resources, National Ilan University, Ilan 260, Taiwan

Tien-Hsi Chen (Corresponding author) General Education Center, Ching Kuo Institute of Management and Health, Keelung 203, Taiwan. E-mail cuora.flavo@msa.hinet.net

Received 24 March 2009. Revision requested 6 May 2009.

Accepted 15 June 2009. urbanization and land development all pose threats to turtles. These threats are particularly acute for those species with a high commercial value. Of the chelonian species traded in Asia, the yellow-margined box turtle Cuora flavomarginata is one of the most threatened (Zhou \& Jiang, 2008).

This species predominantly inhabits mesic forests on low-elevation hills (Mao, 1971; Zhao, 1998). Although C. flavomarginata is widely distributed in central and southern mainland China, Taiwan and the southern Ryukyus of Japan (Mao, 1971; Iverson, 1992; Fong et al., 2002), its status in China and Taiwan is poorly known (Zhao, 1998; Chen et al., 2000) and it faces an uncertain future in Taiwan. The species is categorized as Endangered on the IUCN Red List (Asian Turtle Trade Working Group, 2000) because of extensive habitat loss and commercial exploitation; it was also added to Appendix II of CITES in 2000 to limit overexploitation by international trade. Since 1989 the Taiwanese populations have been protected by the Wildlife Conservation Act as a rare and valuable species.

The status of a given species is usually determined by its distribution and abundance, and the changing rate of these two components (McGowan et al., 1998). For turtle species with high economic value, such as $C$. flavomarginata, range countries have been urged to assess the status, ecology and demography of populations in the wild (Zhao, 1998; Zhou \& Jiang, 2008). We therefore performed a large-scale trapping survey to evaluate the status and distribution of C. flavomarginata in Taiwan and to highlight conservation measures required for the survival of the species there.

\section{Study area}

The trapping survey was conducted at 68 localities throughout Taiwan (Fig. 1), during 2001-2008. At three of these localities (Feitsui, Keelung and Hushan) the survey was extensive (see below). C. flavomarginata had previously been studied in a tributary watershed at the Feitsui Reservoir Protected Area (Chen \& Lue, 1999, 2002, 2008; Lue \& Chen, 1999), which has been blocked from public access, to protect water resources, since 1984; this site provided an opportunity to examine any population changes over time. The habitat consists mainly of primary and secondary evergreen forests (see detailed description in Lue \& Chen, 1999). The site at Keelung is in secondary forest in a mountain basin near a recent development. In 


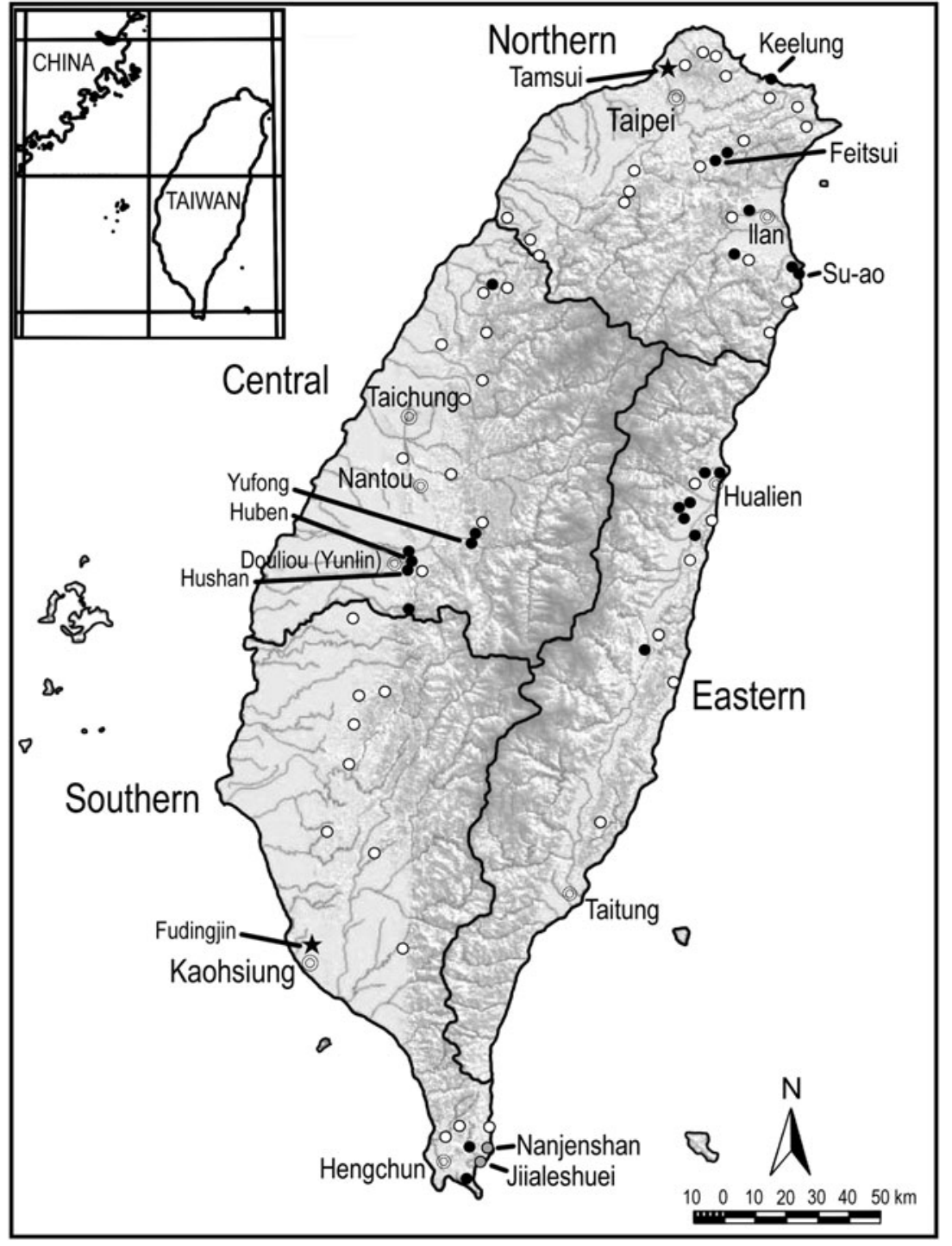

FIG. 1 Sampling sites for the yellowmargined box turtle Cuora flavomarginata in Taiwan. White circles indicate sites where no turtles were captured, black circles sites where turtles were captured (Table 1), and grey circles evidence of presence obtained from other reliable sources (see text for further details). Black stars indicate two historical collection sites. the Hushan Reservoir Planning Zone turtles were trapped intensively for translocation within the submerged and construction areas; the original habitat consisted mainly of well-developed secondary forest and cultivated bamboo (mainly Sinocalamus latiflorus). Elsewhere, we identified potentially suitable habitats for $C$. flavomarginata, such as primary evergreen forest or well-developed secondary forest at elevations $<500 \mathrm{~m}$, using 1:25,000 maps published by the Ministry of Interior, Republic of China and satellite images from Google Earth (2008).

\section{Methods}

To select trapping sites the existence of $C$. flavomarginata in these locations was confirmed by interviews with local residents. We also examined published records and anecdotal reports. Turtles were captured using commercial rodent traps $(29 \times 17 \times 14 \mathrm{~cm})$ in the season when
C. flavomarginata is active (April-October). Traps were baited with banana and set under vegetation to avoid overheating of any captured turtles. At each site at least five traps were set and they were checked 1-2 times per week. If no turtles were captured or encountered in 2 weeks of trapping we assumed the site had no turtles or that they occurred at a low density. We moved the traps to a new site after 2-4 weeks of trapping. Because of the high frequency of trap loss in Hualien, Gukeng (near Douliou) and Sheding (near Hengchun) we collected turtles by searching under vegetation and along trails. At Yufong turtles were captured opportunistically by local volunteers during 2001-2003. Information at Nanjenshan was obtained from Tsai (2007), and at Jiialeshuei by H.-C. Lin (pers. comm.).

This trapping was conducted in conjunction with detailed population studies, for $>_{1}$ year, at Feitsui, Keelung and Hushan. At Feitsui turtles were trapped intensively during September-November 2002 and April-November 
TABLE 1 Numbers of the yellow-margined box turtle Cuora flavomarginata trapped in northern, central, southern and eastern Taiwan (Fig. 1) from 2001 to 2008 .

\begin{tabular}{|c|c|c|c|c|c|c|}
\hline Sampling site & $\begin{array}{l}\text { Unsexed } \\
\text { juveniles }\end{array}$ & Males & Females & Undetermined & Total & $\begin{array}{l}\text { No. of } \\
\text { trap days }\end{array}$ \\
\hline \multicolumn{7}{|c|}{ Northern Taiwan } \\
\hline Feitsui & 17 & 68 & 142 & & 227 & 2,110 \\
\hline Shihding & & 1 & 1 & & 2 & 170 \\
\hline Keelung & 5 & 14 & 33 & & 52 & 1,376 \\
\hline Dajiaosi & 1 & 5 & 5 & & 11 & 129 \\
\hline Sansing & & 2 & 3 & & 5 & 75 \\
\hline $\mathrm{Su}-\mathrm{ao}$ & & 5 & 3 & & 8 & 78 \\
\hline Hudong & 1 & 1 & 4 & & 6 & 60 \\
\hline \multicolumn{7}{|c|}{ Central Taiwan } \\
\hline Shihtan & 1 & 3 & 4 & & 8 & 75 \\
\hline Shueili & & 2 & 3 & & 5 & 490 \\
\hline Yufong $^{1}$ & 1 & 2 & 20 & & 23 & \\
\hline Linnei & 0 & 1 & 6 & & 7 & 28 \\
\hline Huben & 4 & 6 & 23 & 2 & 35 & 421 \\
\hline Hushan & 4 & 19 & 63 & 9 & 95 & 29,100 \\
\hline Gukeng $^{1}$ & & & 1 & & 1 & \\
\hline \multicolumn{7}{|c|}{ Southern Taiwan } \\
\hline Sheding $^{1}$ & & 1 & 2 & & 3 & \\
\hline Manchu & & 1 & & & 1 & 100 \\
\hline Jiialeshuei $^{2}$ & & & 1 & & 1 & \\
\hline Nanjenshan ${ }^{3}$ & & 13 & 1 & & 14 & \\
\hline \multicolumn{7}{|c|}{ Eastern Taiwan } \\
\hline Hualien $^{1}$ & & 1 & 2 & & 3 & \\
\hline Fuguo & & 2 & 2 & & 4 & 76 \\
\hline Liyushan & 4 & 8 & 4 & 1 & 17 & 440 \\
\hline Laosi & & 1 & 1 & & 2 & 92 \\
\hline Shoufong & & 1 & 5 & & 6 & 55 \\
\hline Mijhan & 1 & 2 & 1 & & 4 & 60 \\
\hline Rueisuei & & 1 & 1 & & 2 & 28 \\
\hline
\end{tabular}

${ }^{1}$ Collected by random searches or accidental encounters

${ }^{2}$ Collection data provided by H.-C. Lin

${ }^{3}$ Data obtained from Tsai (2007)

2003. At Keelung turtles were trapped during the active season (April-October) from 2006 to 2008. At Hushan turtles were trapped intensively during September-October 2007 and May-September 2008, and those captured were kept in semi-natural enclosures in nearby abandoned orchards and later translocated to suitable habitats after completion of the construction of the reservoir. At these three sites at least 15 traps were set during each trapping period.

Most of the captured turtles were individually notched on the marginal scutes, for later identification, with a hand saw or triangle file (Cagle, 1939). AVID (AVID Inc., Norco, USA) passive integrated transponder tags were implanted in the Hushan population. Each trapped turtle was sexed on the basis of external secondary sexual characteristics (mainly the position of the cloacal opening). Any turtle without male characteristics and with a carapace length $>100 \mathrm{~mm}$ was assumed to be female. Turtles were released at their capture location after handling and measurement, except at Hushan (see above). In the analyses of population structure we include only sites where $>20$ turtles were captured. In comparisons of body size among different populations we used the measurements of individual turtles from the time of first captures only. We used $G$-tests (Sokal \& Rohlf, 1995) to compare sex ratios and capture rates among different sites or sampling periods.

\section{Results}

We captured a total of 527 individual C. flavomarginata at 23 of the 68 sites (Fig. 1, Table 1) and obtained, in addition, information from Nanjenshan and Jiialeshuei (see above). There were four clusters of localities in which C. flavomarginata were captured: Taipei-Ilan (northern), Nantou-Yunlin (central), Hengchun Peninsula (southern) and northern Hualien-Taitung Valley (eastern). At Feitsui, Keelung and Hushan we captured $>50$ individuals, in broad-leaf evergreen forest at low elevations. However, the capture success at most sites was low (Table 1). C. flavomarginata appears to be locally abundant and restricted to primary and well-developed secondary forest and to the forest edge. 


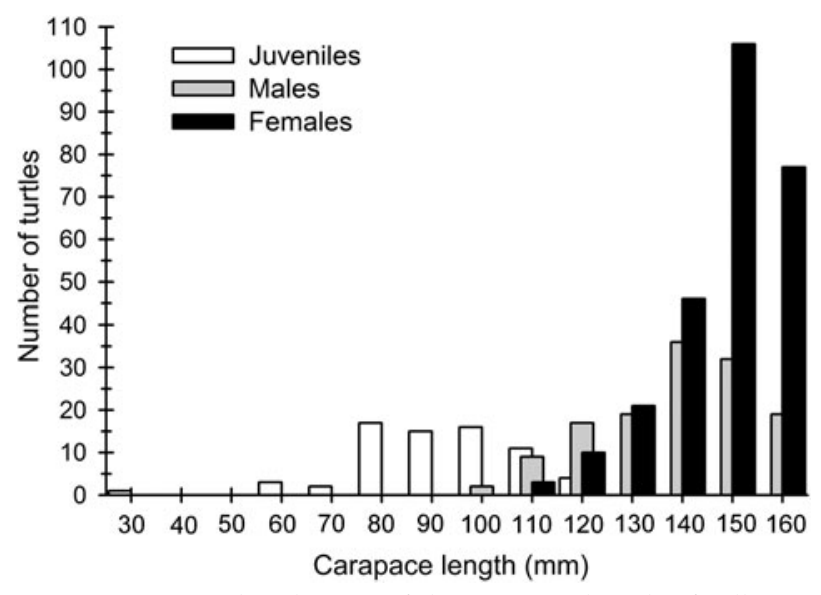

FIG. 2 Frequency distribution of the carapace length of yellowmargined box turtles trapped during 2001-2008.

The overall sex ratio of captured C. flavomarginata was highly female-biased $(G=71.39, \mathrm{P}<0.001)$ and body size composition was dominated by adults (Fig. 2). The proportion of unsexed juveniles was low ( $7.4 \%$ of total captures). In those sites where $>20$ turtles were captured the sex ratio was also significantly female-biased (Feitsui: $G=26.65, \mathrm{P}<$ o.001; Keelung: $G=7.91, \mathrm{P}<0.01$; Yufong: $G=17.09, \mathrm{P}<$ o.oo1; Huben: $G=10.63, \mathrm{P}<0.01$; Hushan: $G=24.90$, $\mathrm{P}<0.001)$.

At Feitsui 227 turtles were captured a total of 892 times, of which $68.6 \%$ of the captured turtles had been marked during 1996-2000 (Chen \& Lue, 1999, 2002). The proportions of unsexed juveniles and both sexes did not change significantly between 1996-2000 and 2002-2003 ( $G=0.90$, $\mathrm{P}=0.639$ ). The distribution of carapace length seems to be relatively stable (Fig. 3). At Keelung 52 turtles were captured a total of 193 times but the capture success was relatively low (Table 1). The mean carapace length of females was significantly larger than those of males at Feitsui and Keelung (Table 2) but there were no significant differences in carapace length between the sexes at Yufong, Huben and Hushan. The trapping success at Feitsui varied seasonally (Fig. 4), being highest in June and lowest in November.

\section{Discussion}

C. flavomarginata was described by Gray (1863) on the basis of a specimen collected by R. Swinhoe from Tamsui (Fig. 1) in northern Taiwan. In the original description C. flavomarginata was reported to be abundant in ponds in the Tamsui area. Some authors (e.g. Stejneger, 1907; Smith, 1931) therefore regarded this turtle as semi-aquatic. Chen (1969) noted that it could be found in wetland and highelevation mountainous areas. However, this species is highly terrestrial, and is found in and around primary and well-developed secondary evergreen forest at low elevations (Chen \& Lue, 1999; Lue \& Chen, 1999). In

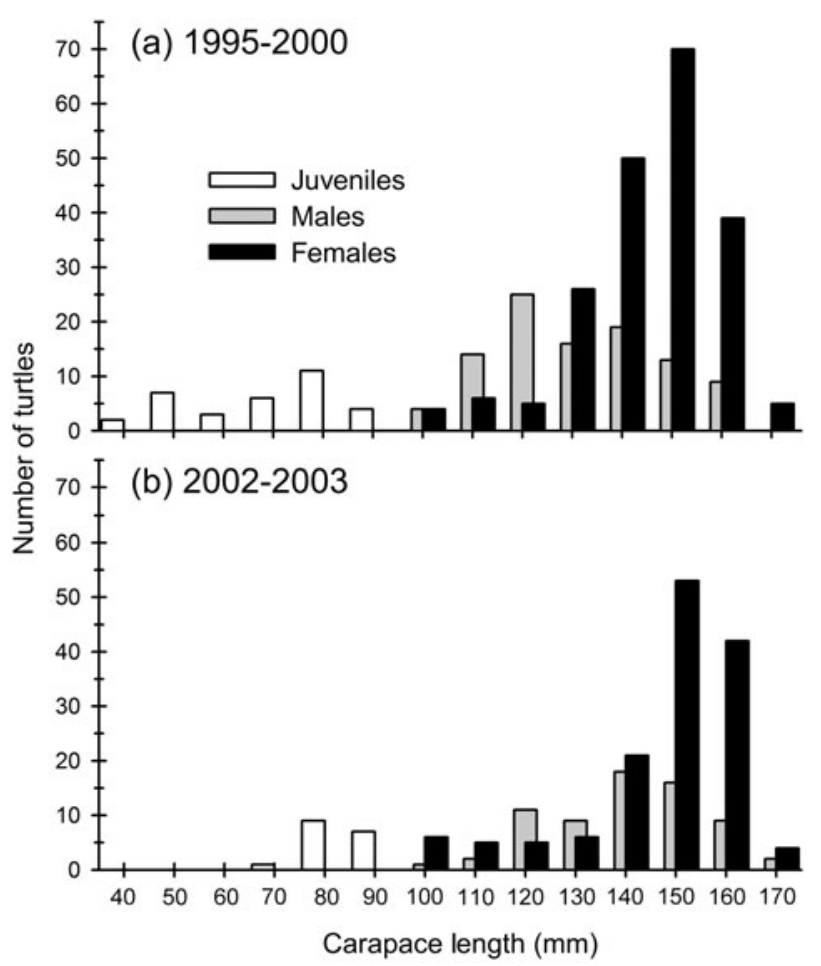

FIG. 3 Frequency distribution of the carapace length of yellowmargined box turtles collected at the Feitsui Reservoir Protected Area (Fig. 1) in (a) 1996-2000 (data from Chen \& Lue, 1999, 2002) and (b) 2002-2003 (this study).

central Taiwan Lin (1996) noted that this turtle was rarely found at altitudes $>500 \mathrm{~m}$. In China C. flavomarginata seems to prefer hilly environments $(200-500 \mathrm{~m})$ and is usually found around the edges of humid forests or bushy areas (Wang, 1991). In southern Ryukyus, Japan, the species prefers mesic evergreen forest rather than montane forests (Ota \& Hamaguchi, 2003). Horikawa (1934) noted that C. flavomarginata was usually seen in forest on low hills and in the foothills, and was sometimes active in nearby wetlands and grasslands. We found C. flavomarginata in wet meadows near forest, such as at Keelung and Su-ao.

Our survey shows that C. flavomarginata is still widely distributed in Taiwan and the population at Feitsui, in contiguous forested habitats with minimal human disturbance, appears to be stable.

The low capture success at most sites, however, suggests that $C$. flavomarginata survives at low population densities. We believe that the historical range of $C$. flavomarginata in Taiwan encompassed the low-elevation evergreen broadleaf forests. However, its range has contracted and populations in lowland areas may have been extirpated because of habitat loss caused by land development. A specimen stored in Kaohsiung High School was from a low-elevation $(20-30 \mathrm{~m})$ area at Fudingjin near Kaohsiung City in the 1930 (B.-H. Lin, pers. comm.). We did not find the species near its type locality (Tamsui) although we found remnant 
TABLE 2 Mean carapace length $( \pm \mathrm{SD}$ ) of the yellow-margined box turtle trapped at the five sites (Fig. 1) with $>20$ captures (Table 1). Numbers in parentheses are sample sizes.

\begin{tabular}{lllll}
\hline & Unsexed juveniles & Males & Females & Significance of difference between sexes \\
\hline Feitsui & $87.8 \pm 6.9(17)$ & $144.1 \pm 14.5(68)$ & $152.0 \pm 14.8(142)$ & $\star * *$ \\
Keelung & $84.8 \pm 11.2(5)$ & $137.2 \pm 17.1(14)$ & $156.5 \pm 15.9(33)$ & $\star * *$ \\
Yufong & $68.1(1)$ & $161.1 \pm 4.3(2)$ & $157.4 \pm 17.9(20)$ & NS \\
Huben & $89.6 \pm 3.8(4)$ & $151.0 \pm 7.7(6)$ & $149.5 \pm 10.5(22)$ & NS \\
Hushan & $73.2 \pm 26.7(4)$ & $140.9 \pm 16.0(16)$ & $144.4 \pm 19.8(60)$ & NS \\
\hline
\end{tabular}

${ }^{\star} \mathrm{NS}$, not significant; ${ }^{* *}=\mathrm{P}<0.001$

populations in suburban areas near the coast, such as at Keelung and Hualien.

Historical collection data for C. flavomarginata in Taiwan includes specimens from Hualien (eastern), Nantou (central) and Pingtung (southern) counties (Field Museum of Natural History, Chicago, USA; Kuntz \& Dien, 1970), and from Hengchun (Pintung County, southern; California Academy of Sciences, San Francisco, USA). The specimens in the National Museum of Natural Science, Taichung, Taiwan, were collected from Hengchun. Chen (1969) reported that this turtle occurred in Ilan, Hualien, Hengchun, Puli (Nantou County) and Pasenshan (Taichung County). However, the locality at Pasenshan may be dubious because of its high altitude (750-1,100 $\mathrm{m})$. We captured some individuals in most of the former collection localities but the abundance of the species may have decreased greatly because the capture success was low at most sites, probably because habitats have been greatly altered since the time of the earlier collections.

Gray (1870) noted that C. flavomarginata may be least abundant in southern Taiwan. We did not collect any individuals near the lowland and hilly areas in southwestern Taiwan but, in the low-elevation forests in the

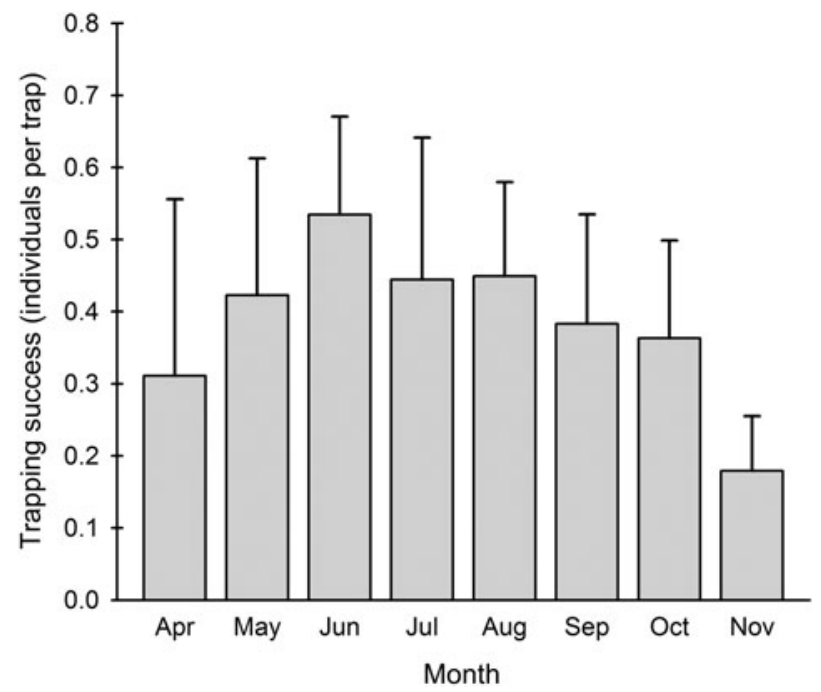

FIG. 4 Mean monthly trapping success $( \pm S D)$ for the yellowmargined box turtle at the Feitsui Reservoir Protected Area during April-November of 2002-2003.
Hengchun Peninsula, Horikawa (1934) reported that he could collect three individuals in 1 hour. Mao (1971) noted that c. 100 turtles had been found in one morning in broadleaf forest near Hengchun. We were only able to collect three individuals in two mornings searching at Sheding (near Hengchun), although it is difficult to compare collection efficiency. Combining the results of Chen \& Lue $(1999,2002)$ and this study a total of 401 C. flavomarginata were captured from 1996 to 2003 at Feitsui. However, only about three individuals were found there in 6 hours by intensive searching in forest in 1996-1997 (Chen, 1998).

Unbalanced sex ratios have been commonly reported in freshwater turtle populations (Gibbons, 1970; Bury, 1979), and this is often attributed to sampling biases (Gibbons, 1990). We found the sex ratio of C. flavomarginata to be significantly female-biased, and it did not change between 1996-1997 and 2002-2003 in the Feitsui population. The causes of the female-biased sex ratio of $C$. flavomarginata are unclear. The body size of the $C$. flavomarginata collected shows that individuals captured were predominantly adults. Terrestrial turtles may suffer high mortality in early stage of their life history (Frazer et al., 1990; Iverson, 1991). Nevertheless, juveniles were probably underrepresented in our data because of the difficulties of finding them in the dense forest understorey.

Habitat loss, expansion of the road network and habitat fragmentation have contributed to the decline of the terrestrial box turtle Terrapene carolina in the USA (Stickel, 1978; Williams \& Parker, 1987; Nazdrowicz et al., 2008). The situation for C. flavomarginata in Taiwan seems to be similar. Deforestation and habitat fragmentation in low altitude evergreen forest seem to be the main threats to this species (Chen et al., 2000). In addition, female C. flavomarginata usually move to open habitats near the border of evergreen forests in summer (Lue \& Chen, 1999) and this may make the species more vulnerable to illegal collection.

The illegal cross-border trade may pose a serious threat to the long-term survival of $C$. flavomarginata, especially illegal collection for the pet and food markets in China. Many cases of cross-border trade to continental China have been reported; $>2,300$ individuals of $C$. flavomarginata were confiscated in 2006-2009 (T.-H. Chen, pers. obs.). With low reproductive rates and late maturity (Iverson, 
1991), the unregulated exploitation of C. flavomarginata is unsustainable.

The low capture success in our survey and the loss of habitat for the remaining populations indicates that most populations of C. flavomarginata require conservation attention. Most of the major localities of $C$. flavomarginata in Taiwan are not included in the existing protected area system. Even in protected areas, such as the Kenting National Park (near Hengchun), the pressure of illegal poaching is high (Tsai, 2007). Although it is difficult to protect habitats near highly developed areas such as Keelung and Huanlien, preservation of some habitats for $C$. flavomarginata in rural areas should be considered.

The most essential measure for the conservation of $C$. flavomarginata in Taiwan is to secure and conserve some relatively undisturbed habitats at low elevations, such as the Feitsui Reservoir Protected Area (which is protected for its water resources rather than for wildlife) or within national parks, where some box turtle populations are found. It is also important to monitor illegal capture and trade in this species, especially when such activities are conducted commercially. To develop an effective and comprehensive conservation programme for $C$. flavomarginata more detailed field surveys are needed to assess and monitor population trends, especially in highly developed lowland regions.

\section{Acknowledgements}

We thank E.Y. Tsoa and three anonymous reviewers for their valuable comments, and the following, who assisted with fieldwork: S.-L. Liu, Y.-D. Lue, S.-L. Chen, F.-S. Chen and S. Wang. This study was supported financially by the National Science Council, Council of Agriculture, Ministry of Economic Affairs (Water Resources Agency, Central Region Water Resources Office), Taiwan Endemic Species Research Institute, Republic of China (Grants to T.-H. Chen: NSC92-2311-B-396-002, NSC93-2311-B-396-001, 92AS-4.1.4-FC-R1, 93AS-4.1.1-FB-e2, 94AS-9.1.7-FB-e1, 95AS-11.5.3-FB-e1; T.-E. Lin: WRA97-150) and conducted under the permits from the Council of Agriculture (Permits to T.-H. Chen: 900115339, 0910116910, 0920127668, 0931614045, 0941611580; TESRI: 0931606790, 0970139786, 0971610794).

\section{References}

Asian Turtle Trade Working Group (2000) Cuora flavomarginata. In IUCN Red List of Threatened Species v. 2010.1. Http://www. iucnredlist.org [accessed 23 April 2010].

BURY, R.B. (1979) Population ecology of freshwater turtles. In Turtles: Perspectives and Research (eds M. Harless \& H. Morlock), pp. 571602. Wiley and Sons, New York, USA.

CAgle, F.R. (1939) A system of marking turtles for future identification. Copeia, 1939, 170-173.
Chen, J.T.F. (1969) A Synopsis of the Vertebrates of Taiwan. Commercial Press, Taipei, Taiwan.

Chen, T.-H. (1998) Life histories of the Chinese stripe-necked turtle (Ocadia sinensis) and the yellow-margined box turtle (Cistoclemmys flavomarginata) in northern Taiwan. PhD thesis, National Taiwan Normal University, Taipei, Taiwan. [In Chinese with English abstract]

Chen, T.-H., Lin, H.-C. \& Chang, H.-C. (2000) Current status and utilization of the chelonians in Taiwan. In Asian Turtle Trade: Proceedings of Workshop on Conservation and Trade of Freshwater Turtles and Tortoises in Asia (eds P.P. van Dijk, B.L. Stuart \& A.G.J. Rhodin). Chelonian Research Monographs, 2, 45-51.

Chen, T.-H. \& Lue, K.-Y. (1999) Population characteristics and egg production of the yellow-margined box turtle, Cuora flavomarginata flavomarginata, in northern Taiwan. Herpetologica, 55, 487-498.

Chen, T.-H. \& Lue, K.-Y. (2002) Growth patterns of the yellowmargined box turtle (Cuora flavomarginata) in northern Taiwan. Journal of Herpetology, 36, 201-208.

Chen, T.-H. \& Lue, K.-Y. (2008) Thermal preference of the yellowmargined box turtle (Cuora flavomarginata) (Testudines: Geoemydidae) inhabiting a mesic lowland forest, northern Taiwan. Amphibia-Reptilia, 29, 513-522.

FonG, J.J., Parham, J.F. \& Fu, J. (2002) A reassessment of the distribution of Cuora flavomarginata Gray 1863 on mainland China. Russian Journal of Herpetology, 9, 9-14.

Frazer, N.B., Gibbons, J.W. \& Greene, J.L. (1990) Life tables of a slider turtle population. In Life History and Ecology of the Slider Turtle (ed. J.W. Gibbons), pp. 183-200. Smithsonian, Washington, DC, USA.

Gibions, J.W. (1970) Sex ratios in turtles. Researches on Population Ecology, 12, 252-254.

Gibions, J.W. (1990) Sex ratios and their significance among turtle populations. In Life History and Ecology of the Slider Turtle (ed. J.W. Gibbons), pp. 172-182. Smithsonian, Washington, DC, USA.

Gibions, J.W., Scott, D.E., Ryan, T.J., Buhlmann, K.A., Tuberville, T.D., Metts, B.S. et al. (2000) The global decline of reptiles, déjà vu amphibians. BioScience, 50, 653-666.

Google EARTH (2008) Http://earth.google.com/ [accessed 15 March 2008].

Gray, J.E. (1863) Observations on the box tortoises, with the descriptions of three new Asiatic species. Proceedings of the Zoological Society of London, 1863, 173-177.

Gray, J.E. (1870) Supplement to the Catalogue of Shield Reptiles in the Collection of the British Museum. British Museum, London, UK.

Horikawa, Y. (1934) Turtles of Taiwan. The Taiwan Jiho, 181, 7-16. [in Japanese]

Iverson, J.B. (1991) Patterns of survivorship in turtles. Canadian Journal of Zoology, 69, 385-391.

Iverson, J.B. (1992) A Revised Checklist with Distribution Maps of the Turtles of the World. Privately printed, Richmond, Indiana, USA.

KuntZ, R.E. \& Dien, Z.M. (1970) Vertebrates of Taiwan taken for parasitological and biomedical studies by US Naval Medical Research Unit No. 2, Taipei, Taiwan, Republic of China. Quarterly Journal of Taiwan Museum, 23, 1-37.

Lin, H.-C. (1996) Reptiles of Nantou County. Taiwan Endemic Species Research Institute, Chichi, Taiwan. [in Chinese]

Lue, K.-Y. \& Chen, T.-H. (1999) Activity, movement patterns, and home range of the yellow-margined box turtle (Cuora flavomarginata) in northern Taiwan. Journal of Herpetology, 33, 590-600.

Ma o, S.H. (1971) Turtles of Taiwan. Commercial Press, Taipei, Taiwan.

McGowan, P., Gillman, M. \& Dodd, M. (1998) Assessing the status of poorly known species: lessons from partridges and pheasants of Southeast Asia. Biological Conservation, $83,1-7$. 
Nazdrowicz, N.H., Bowman, J.L. \& Roth, R.R. (2008) Population ecology of the eastern box turtle in a fragmented landscape. Journal of Wildlife Management, 72, 745-753.

Ота, H. \& Hamaguchi, H. (eds) (2003) Report on the Biology and Conservation of the Two Endangered Turtles of Okinawa, Geoemyda japonica and Cuora flavomarginata evelynae (Testudines: Bataguridae). The Survey Reports on the Current Status of the Natural Monuments of Okinawa Prefecture, 41. Okinawa Prefectural Board of Education, Naha, Japan. [in Japanese]

Sм тт н, M.A. (1931) The Fauna of British India, Including Ceylon and Burma. Reptilia and Amphibian, Vol. 1 Loricata, Testudines. Taylor \& Francis, London, UK.

Sokal, R.R. \& Rohlf, F.J. (1995) Biometry: The Principles and Practice of Statistics in Biological Research, 3rd edition. Freeman, New York, USA.

STEJNeger, L. (1907) Herpetology of Japan and adjacent territory. Bulletin of United States National Museum, 58, 1-577.

STICKeL, L.F. (1978) Changes in box turtle population during three decades. Copeia, 1978, 221-225.

Tsai, C.-F. (2007) Daily activity patterns and home range of Cuora flavomarginata in a monsoon forest in southern Taiwan. MSc thesis, National Cheng Kung University, Tainan, Taiwan.

van Dijk, P.P., Stuart, B.L. \& Rhodin, A.G.J. (eds) (200o) Asian Turtle Trade: Proceedings of a Workshop on Conservation and Trade of Freshwater Turtles and Tortoises in Asia. Chelonian Research Foundation, Lunenberg, USA.
W ANG, Y. (1991) Cistoclemmys flavomarginata. In The Amphibian and Reptilian Fauna of Anhui (ed. B. Chen), pp. 183-187. Anhui Publishing House of Science and Technology, Hefei, China. [in Chinese]

Williams, JR, E.C. \& Parker, W.S. (1987) A long-term study of a box turtle (Terrapene carolina) population at Allee Memorial Woods, Indiana, with emphasis on survivorship. Herpetologica, $43,328-335$.

Zна , E. (1998) China Red Data Book of Endangered Animals: Amphibia and Reptilia. Science Press, Beijing, China.

ZHOU, Z. \& JIANG, Z. (2008) Characteristics and risk assessment of international trade in tortoises and freshwater turtles in China. Chelonian Conservation and Biology, 7, 28-36.

\section{Biographical sketches}

$\mathrm{Y}_{\mathrm{I}}-\mathrm{FU}_{\mathrm{U}} \mathrm{L}_{\mathrm{IN}}$ is working on the conservation ecology of threatened box turtles in Taiwan. SHENG-HAI WU is interested in the comparative anatomy, ecology and systematics of vertebrates, especially of the herpetofauna. TE-EN LiN researches the ecology and physiological ecology of the herpetofauna of Taiwan, including introduced amphibians and reptiles. JEAN-JAY MAO devotes most of his research to the population ecology of reptiles. TIEN-HSI CHEN has worked mainly on the ecology and conservation of the freshwater turtles of Taiwan. 